Original Article

\title{
ANALYTICAL METHOD DEVELOPMENT AND VALIDATION FOR KNOWN AND UNKNOWN IMPURITIES PROFILING FOR CARVEDILOL PHARMACEUTICAL DOSAGE FORM (TABLETS)
}

\author{
NITIN MAHAJAN ${ }^{*}$, SUPARNA DESHMUKH ${ }^{2}$, MAZAHAR FAROOQUI ${ }^{1}$
}

1Post Graduate and Research Centre, Department of Chemistry, Maulana Azad College of Arts, Science and Commerce, Dr. Babasaheb Ambedkar Marathwada University, Aurangabad, Maharashtra, 431001, India, ${ }^{2}$ Department of Chemistry, S. K Gandhi college, Kada, Tal:

Asthi, Dist: Beed, Maharashtra, 414202, India

"Email: mahajan1925@gmail.com

Received: 08 Aug 2021, Revised and Accepted: 06 Oct 2021

\begin{abstract}
Objective: The aim of the research work to develop a simple, sensitive, rugged, robust and specific novel gradient stability indicating reverse phase HPLC method for quantitative determination of known and unknown impurities profiling of Carvedilol pharmaceutical dosage forms (Tablets).

Methods: Chromatographic separation has been achieved on an Inertsil ODS 3V column (150 mm x $4.6 \mathrm{~mm}, 5 \mu \mathrm{m})$ with mobile phase consisting Mobile phase-A (Water, Acetonitrile and Trifluroacetic acid in the ratio of 80:20:0.1 v/v/v respectively and pH adjusted to 2.0 with dilute potassium hydroxide solution) and Mobile phase-B (Water and acetonitrile in the ratio of 100:900 v/v respectively) delivered at flow rate of $1.0 \mathrm{ml} \mathrm{min}{ }^{-1}$ and the detection wavelength $240 \mathrm{~nm}$. The column compartment temperature maintained at $40^{\circ} \mathrm{C}$.
\end{abstract}

Results: Resolution between Carvedilol and its impurities has been achieved greater than 1.5. The developed method was validated as per ICH guidelines. Analytical method found Precise, Linear, accurate, specific, rugged and robust.

Conclusion: Developed and validated novel analytical method can be used to for impurity profile analysis of Carvedilol Pharmaceutical dosage form (Tablets).

Keywords: Carvedilol, Method development, Validation, Impurities, Related substances, ICH guidelines

(C) 2021 The Authors. Published by Innovare Academic Sciences Pvt Ltd. This is an open access article under the CC BY license (https://creativecommons.org/licenses/by/4.0/) DOI: https://dx.doi.org/10.22159/ijcpr.2021v13i6.1922 Journal homepage: https://innovareacademics.in/journals/index.php/ijcpr

\section{INTRODUCTION}

Carvedilol chemically it is named, $( \pm)-1$-(carbazol-4-yloxy)-3-((2-omethoxyphenoxy) ethyl) amino)-2-propanol. Carvedilol is a racemic mixture where the $S(-)$ enantiomer is a beta adrenoceptor blocker and the $\mathrm{R} \mathrm{(+)} \mathrm{enantiomer} \mathrm{is} \mathrm{both} \mathrm{a} \mathrm{beta} \mathrm{and} \mathrm{alpha-} 1$ adrenoceptor blocker and is currently used to treat heart failure, left ventricular dysfunction and hypertension $[1,2]$. Carvedilol shows a greater antioxidant activity than other commonly used beta-blockers $[3,4]$. It has been prescribed as an antihypertensive agent, an antiangina agent [5-8]. The dual action of carvedilol is advantageous in combination therapies as moderate doses of 2 drugs have a decreased incidence of adverse effects compared to high dose monotherapy in the treatment of moderate hypertension [9]. Impurity profiling (known and unknown), generation of degradents and identification of degradents of active pharmaceutical ingredients (API) and pharmaceutical dosage form (tablets) is one of the most challenging tasks to pharmaceutical analytical scientists in pharma industry [10]. The presence of degradants, unknown impurities and unknown chemicals at lower levels may affect therapeutic efficacy as well as the safety of pharmaceutical dosage form. As a result, all drug regulators in different countries have established maximum permissible limits for known and unknown impurities both in Active Pharmaceutical Ingredients and pharmaceutical dosage forms $[11,12]$. All the major international pharmaceutical regulators require that the study of known and unknown impurities profiles of drug substances and drug products be performed using a suitable stability indicating validated analytical method [13-17].

The comprehensive literature review found that the several RPHPLC method reported for determination of assay of Carvedilol alone [18-28] and with combination of other drug $[29,30]$ and very few methods have been reported to determine related substances
[31-34] and metabolites [35] of Carvedilol. These methods used a column oven temperature greater than $40{ }^{\circ} \mathrm{C}$ which significantly reduces the life of the HPLC column and therefore is not economically feasible for routine testing of the drug substance or drug product for a long time. These methods are not discussed on Carvedilol EP Impurity-D. The unique feature of this new method is separation of Carvedilol EP Impurity-D from main drug as well as from its known and unknown impurities. The method specified for determining of impurities in drug substance $[31,32]$ and not for the pharmaceutical dosage form (tablets) that involve excipient interference and challenge of extraction of the drug substance from its excipient with accurate quantification of impurities and its profile.

USP monograph method as well as other method [32] is available for determination of know impurities of drug substance and not for pharmaceutical formulation (tablets). USP method for drug substance involve preparation of standard solution using impurities reference standard which is not cost effective. The method which is reported for Pharmaceutical dose i.e. Tablets formulation discussed only two impurities profile [33]. The USP monograph method is available for Pharmaceutical dose i.e. Tablets formulation but has not been discussed regarding the known impurities profile. The related substance method reported for pharmaceutical formulation [34] involves the use of the impurities standard each time for the preparation of a system suitability solution that is not economically feasible.

The other unique feature of the new method is that it is highly sensitive and superior in terms of the limit of quantification of known and unknown impurities compared to other methods [34]. The chemical name of Carvedilol and its impurities are shown in table 1. The structure of Carvedilol and its impurities are shown in fig. 1, 2, 3, 4 and fig. 5. 
Table 1: Chemical name of carvedilol and its impurities

\begin{tabular}{|c|c|c|}
\hline Compound name & Chemical name & Molecular weight \\
\hline Carvedilol & ( \pm )-1-(Carbazol-4-yloxy)-3-[\{2-(0-methoxyphenoxy) ethyl $\}$ amino]-2-propanol & 406.47 \\
\hline Carvedilol EP Impurity-A & $\begin{array}{l}\text { 1-(4-(2-Hydroxy-3-(2-(2-methoxyphenoxy) ethylamino) propoxy)-9H-carbazol-9-yl)-3-(2- } \\
\text { (2-methoxyphenoxy) ethylamino) propan-2-ol }\end{array}$ & 629.74 \\
\hline Carvedilol EP Impurity-B & 3,3'-(2-(2-Methoxyphenoxy)ethylazanediyl)bis(1-(9H-carbazol-4-yloxy) propan-2-ol) & 645.74 \\
\hline Carvedilol EP Impurity-C & 1-(9H-Carbazol-4-yloxy)-3-(benzyl(2-(2-methoxyphenoxy)ethyl) amino)propan-2-ol & 496.6 \\
\hline Carvedilol EP Impurity-D & $\begin{array}{l}\text { 1-(9H-Carbazol-4-yloxy)-3-[4-[2-hydroxy-3-[[2-(2-methoxyphenoxy)ethyl]amino]propoxy] } \\
\text { 9H-carbazol-9-yl] propan-2-ol }\end{array}$ & 645.76 \\
\hline
\end{tabular}<smiles>COc1ccccc1OCCNCC(O)COc1cccc2[nH]c3ccccc3c12</smiles>

Fig. 1: Carvedilol<smiles>COc1ccccc1OCCNCC(O)COc1cccc2c1c1ccccc1n2CC(O)CNCCOc1ccccc1OC</smiles>

Fig. 2: Carvedilol EP Impurity-A<smiles>COc1ccccc1OCCN(CC(O)COc1cccc2[nH]c3ccccc3c12)CC(O)COc1cccc2[nH]c3ccccc3c12</smiles>

Fig. 3: Carvedilol EP Impurity-B<smiles>COc1ccccc1OCCN(Cc1ccccc1)CC(O)COc1cccc2[nH]c3ccccc3c12</smiles>

Fig. 4: Carvedilol EP Impurity-C

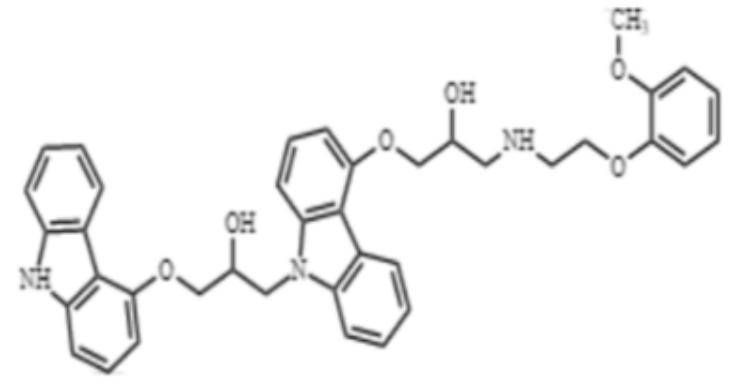

Fig. 5: Carvedilol EP impurity-D

\section{MATERIALS AND METHODS}

\section{Regents and materials}

Marketed samples of Cholecalciferol tablets were used in developing analytical method and validation of analytical method.

Cholecalciferol associated related substances (impurities) were obtained from OLYMPUS Chemical and Fertilizers from Mumbai, India. Trifluroacetic acid and Acetonitrile was procured from spectrochem Limited, HPLC grade water was obtained from Milli-Q purification system. 0.45 $\mu \mathrm{m}$ PVDF filter used of Merck India make.

\section{Instrumentation}

HPLC (Make: Waters) equipped with an integrated autosampler and a quaternary gradient pump was used. The column holder having temperature controlled and an Ultra violet (UV)/Photodiode array detector (PDA) was used for the development and analytical method validation. Chromatographic data was acquired using empower software.

\section{Chromatographic conditions}

Inertsil ODS $3 \mathrm{~V}(150 \times 4.6) \mathrm{mm}, 5 \mu \mathrm{m}$ column was used. The column holder temperature maintained at $40{ }^{\circ} \mathrm{C}$. The mobile phase consist of a different composition of buffer solution and organic solvents. Mobile Phase- $\mathrm{A}$ is mixture of Water, Acetonitrile and Trifluroacetic acid in the ratio 80:20: $0.1 \mathrm{v} / \mathrm{v} / \mathrm{v}$ and $\mathrm{pH}$ of this mixture adjusted to 2.0 with dilute potassium hydroxide solution.

Mobile Phase-B is mixture water and Acetonitrile in the ratio 10:90 $\mathrm{v} / \mathrm{v}$.

HPLC gradient programme run mentioned in table 2.

Table 2: Mobile phase programme for gradient elution

\begin{tabular}{|c|c|c|c|}
\hline Time (min) & Flow (ml min-1) & Mobile phase-A (\%) & Mobile phase-B (\%) \\
\hline 0 & 1.0 & 80 & 20 \\
\hline 10 & 1.0 & 80 & 20 \\
\hline 30 & 1.0 & 60 & 40 \\
\hline 40 & 1.0 & 60 & 40 \\
\hline 50 & 1.0 & 80 & 20 \\
\hline 60 & 1.0 & 80 & 20 \\
\hline
\end{tabular}

\section{Diluent}

Mixture of $0.02 \mathrm{M} \mathrm{KH}_{2} \mathrm{O}_{4}$ buffer $\mathrm{pH} 2.5$ and Acetonitrile in the ratio $65: 35 \mathrm{v} / \mathrm{v}$

\section{Standard solution preparations}

Solution containing $2 \mu \mathrm{g} \mathrm{ml}^{-1}$ of Carvedilol standard prepared in diluent. 


\section{Sample solution}

Accurately weigh and transferred tablets powder equivalent to $25 \mathrm{mg}$ of Carvedilol into $25 \mathrm{ml}$ volumetric flask, Add about $20 \mathrm{ml}$ of diluent sonicated for $30 \mathrm{~min}$ with intermittent shaking and make the volume with diluent. Filtered through $0.45 \mu \mathrm{m}$ PVDF filter after discarding first five $\mathrm{ml}$ of filtrate. (Sample concentration: $1000 \mu \mathrm{g} \mathrm{ml}^{-1}$ )

\section{RESULTS AND DISCUSSION}

\section{Optimization of chromatographic conditions}

Molecular structures of Carvedilol (fig. 1) shows that all the related compounds of Carvedilol are basic in nature. Carvedilol and its known impurities wavelength scan was performed and impurities shows maximum response at $240 \mathrm{~nm}$ wavelength, hence this wavelength is chosen for final quantification of impurities.

Carvedilol, Carvedilol EP Impurity-A, Carvedilol EP Impurity-B, Carvedilol EP Impurity-C and Carvedilol EP Impurity-D molecular structure (fig. 1-5 respectively) shows that these structures contains amine groups due to which showing polar in nature properties.

The development of the method began with the purpose of separating all known, unknown and degradents impurities that are generated during stability.

In initial method development experiments C8 stationary phase column with orthophosphoric acid buffer $\mathrm{pH} 3.5$ and methanol was used as mobile phase. The combination of orthophosphoric acid and methanol indicates early elution of impurities and poor resolution of known impurities. Different development trails runs were carried out to increase the retention time, to reduce the baseline drift and improve the resolution of known and unknown impurities. However a better separation between the impurities has not been achieved. Therefore, column C8 was not considered for further development trials.

Apart from stationary phase, the mobile phase, additives and organic modifiers are also considered in further development trials to obtain good resolution, Gaussian peak shape and sharp peak response for impurities.

With the use of the stationary phase column C18 and with the use of different solvents (mobile phase) a better resolution (greater than 1.5) was achieved between known and unknown impurities and also separated from the main drug (Carvedilol).

After extensive study, the method was finalized on Inertsil ODS $3 \mathrm{~V}(150 \times 4.6) \mathrm{mm}, 5 \mu \mathrm{m}$ using the mobile phase of variable composition, Mobile phase-A consist of Water, Acetonitrile and Trifluroacetic acid in the ratio of $80: 20: 0.1 \mathrm{v} / \mathrm{v} / \mathrm{v}$ respectively and $\mathrm{pH}$ adjusted to 2.0 with dilute potassium hydroxide solution and Mobile phase-B consist of water and acetonitrile in the ratio of $100: 900 \mathrm{v} / \mathrm{v}$ respectively. The mobile phase maintained at flow rate of $1.0 \mathrm{ml} \mathrm{min-1}$ and column oven temperature kept at $40{ }^{\circ} \mathrm{C}$. The detector wavelength chosen $240 \mathrm{~nm}$ at which all impurities shows maximum response. A representative HPLC chromatogram (fig. 8) shows the peaks well resolved with respect to each other.

Fig. 6-13 represent the Blank, Standard, Placebo, Spike sample, Individual known Carvedilol EP Impurity-A, Carvedilol EP Impurity$\mathrm{B}$, Carvedilol EP Impurity-C and Carvedilol EP Impurity-D chromatograms respectively.

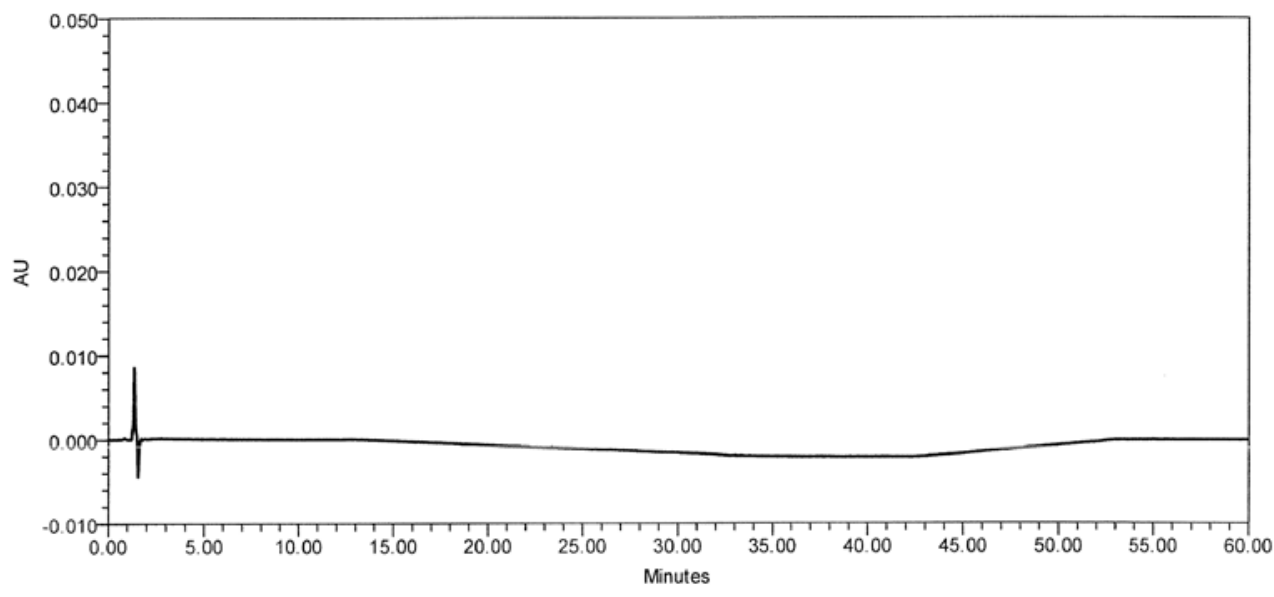

Fig. 6: Typical HPLC chromatogram of blank

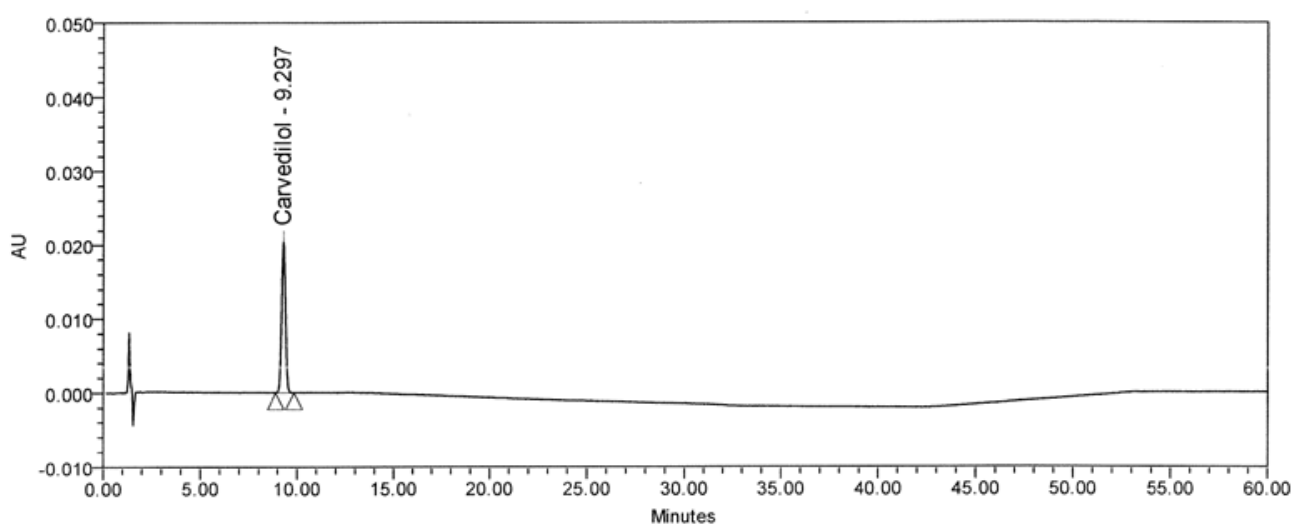

Fig. 7: Typical HPLC chromatogram of standard 


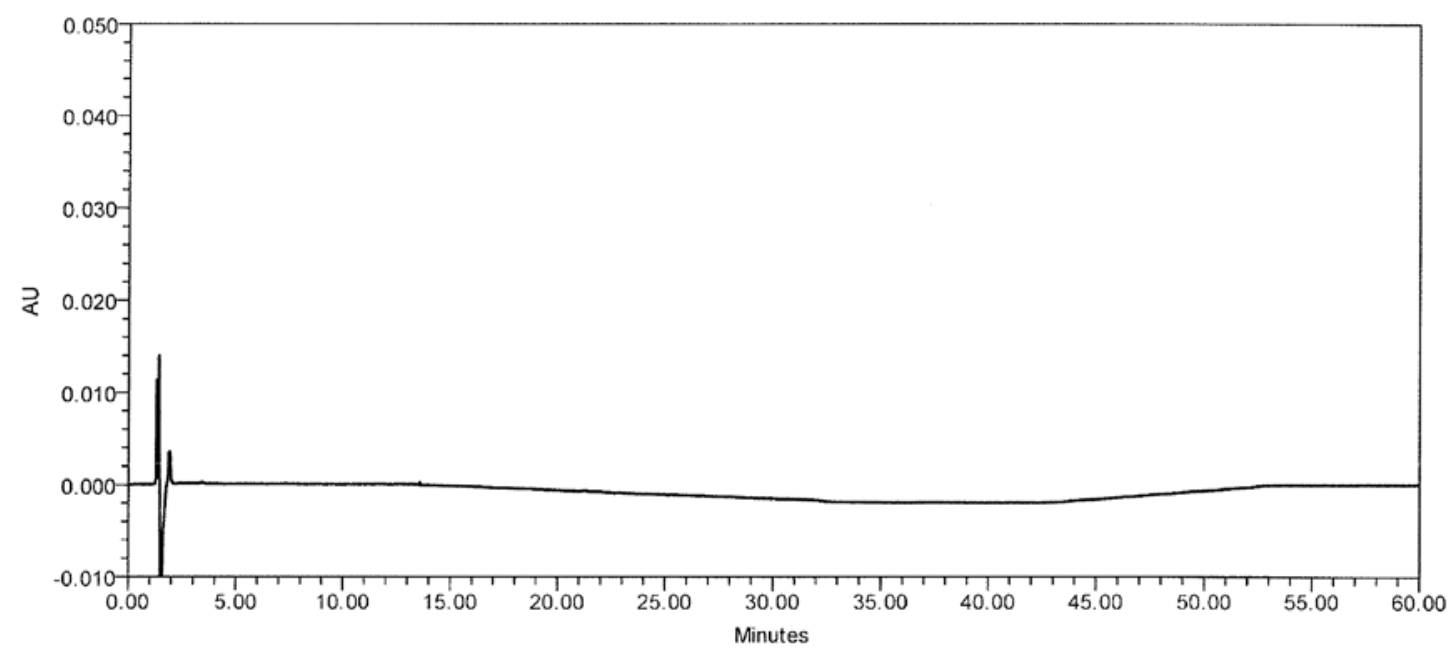

Fig. 8: Typical HPLC chromatogram of placebo solution

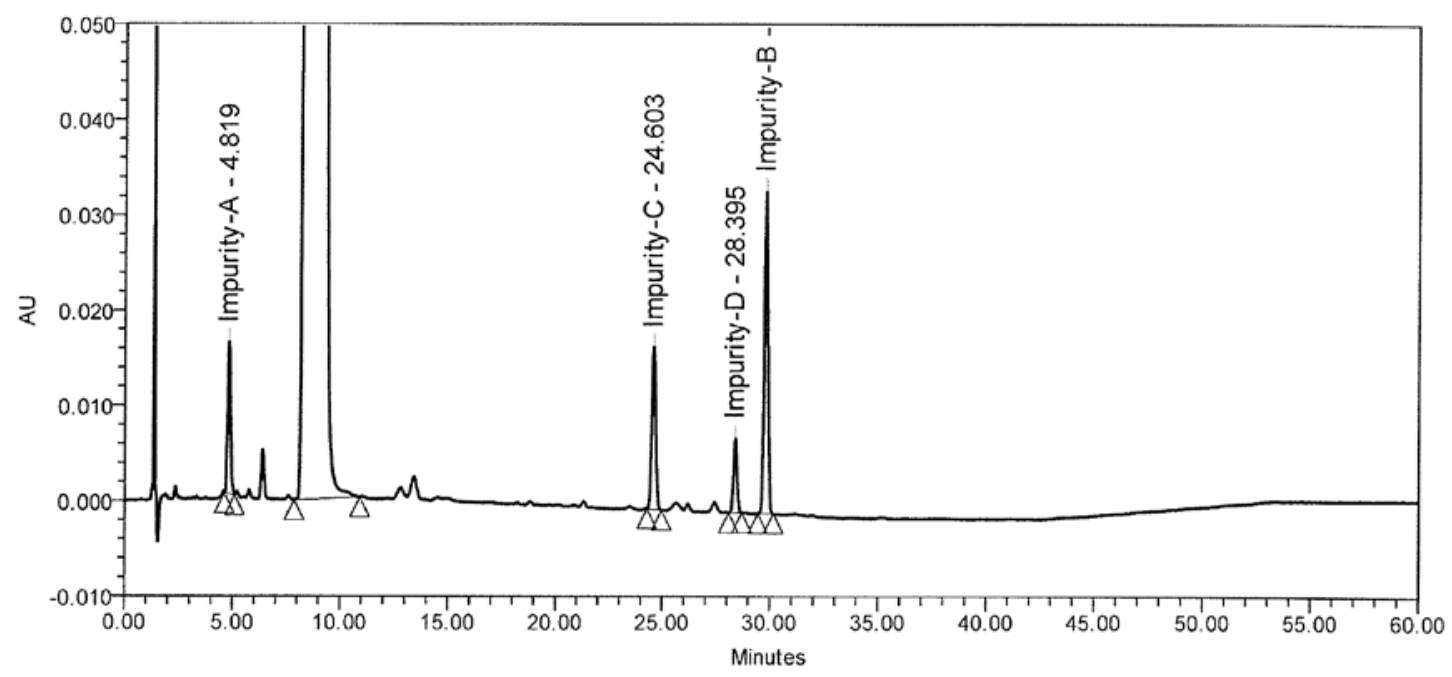

Fig. 9: Typical HPLC chromatogram of spike sample

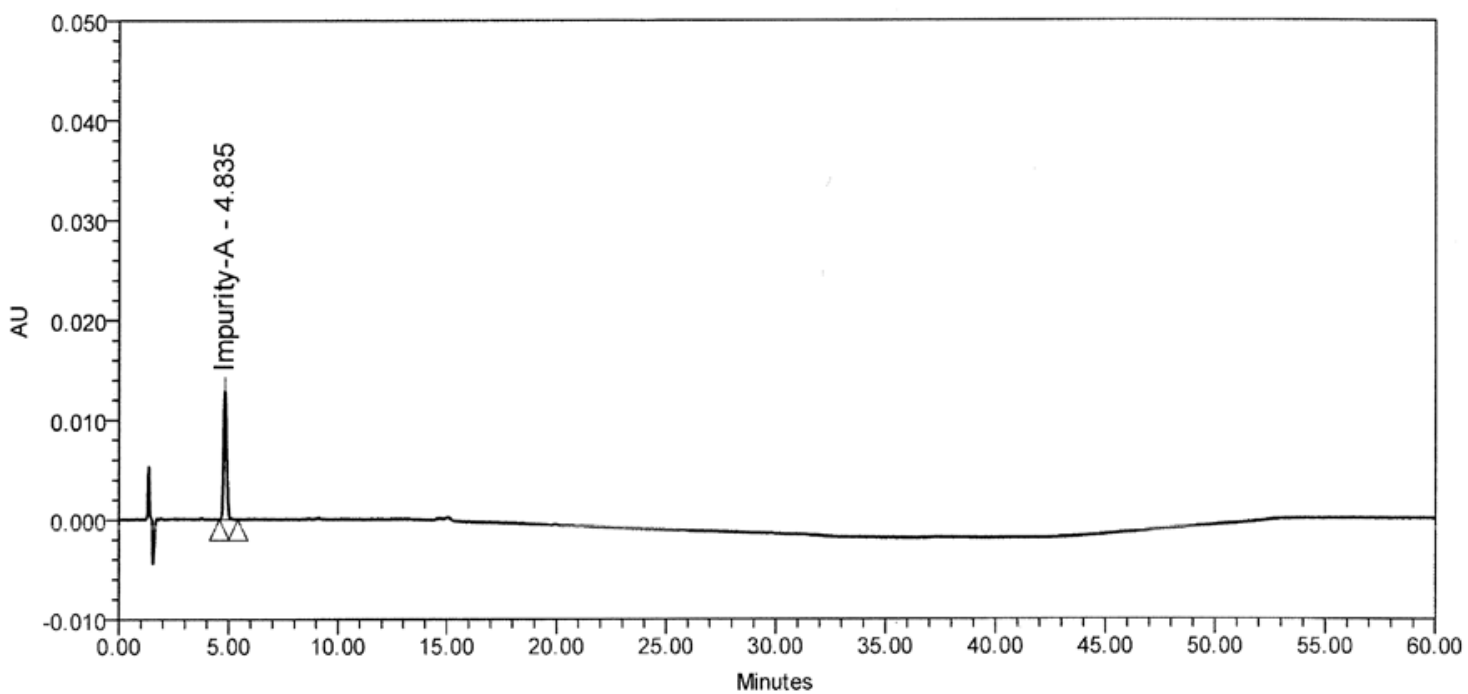

Fig. 10: Typical HPLC chromatogram of carvedilol EP impurity-A 


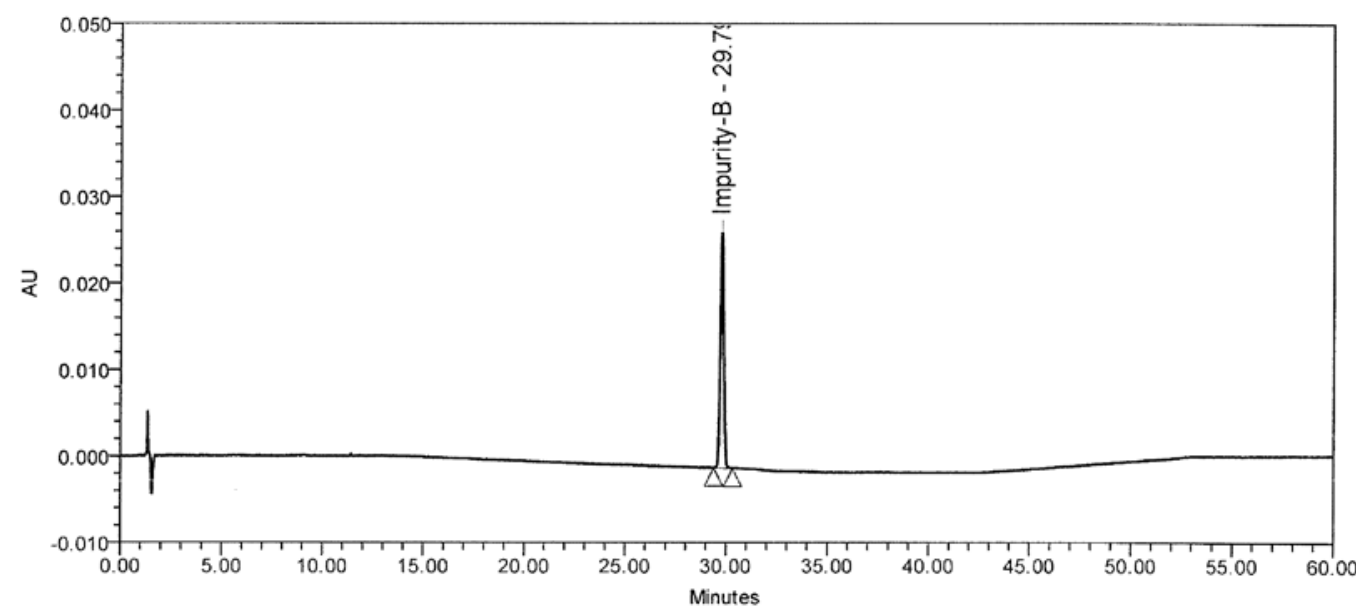

Fig. 11: Typical HPLC chromatogram of carvedilol EP Impurity-B

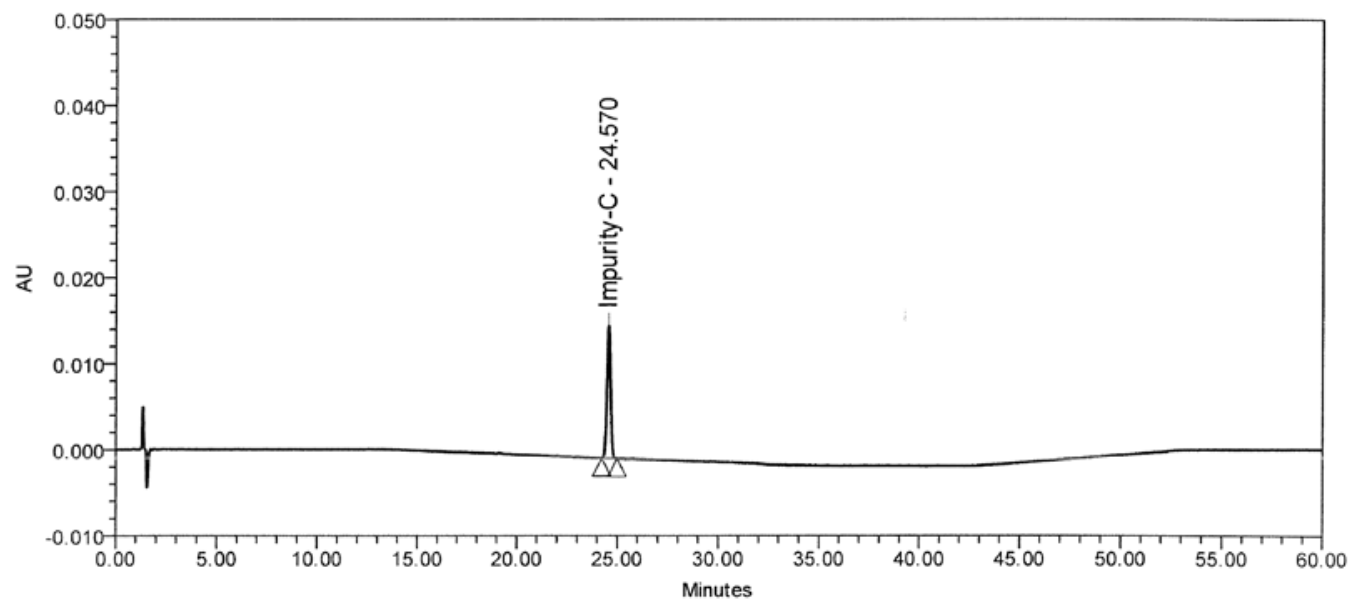

Fig. 12: Typical HPLC chromatogram of carvedilol EP Impurity-C

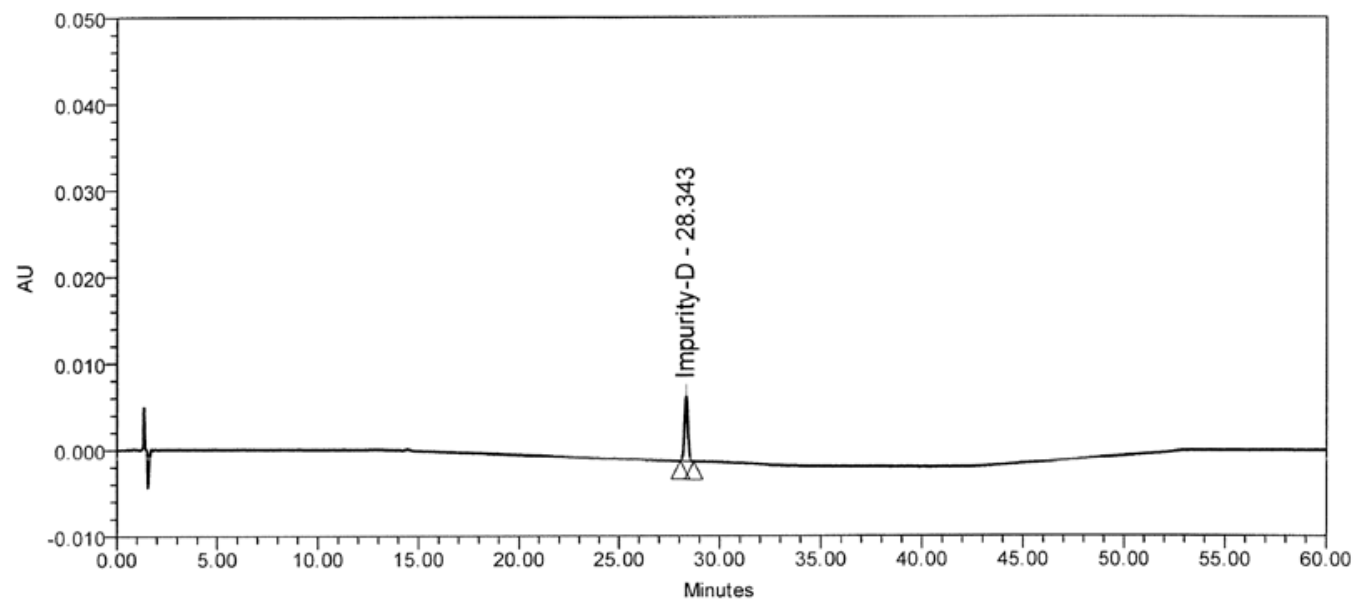

Fig. 13: Typical HPLC chromatogram of carvedilol EP Impurity-D

\section{Solution stability of sample solution and standard solution}

The stability of the sample solution and standard solution was verified by injecting the sample solution and standard solution at initial and different regular intervals into the proposed method at room temperature.
The stability of the sample solution was checked on the basis of the formation of additional peaks and no increase in the known and unknown impurity of $0.04 \%$ from its original level.

On verifying the formation of additional peaks, it was found that no additional peaks were formed and no increase of present known and 
unknown impurity by $0.04 \%$ level from its initial level to till $48 \mathrm{~h}$ indicating that the sample solution is stable for about $48 \mathrm{~h}$ at room temperature.

The stability of the standard solution was evaluated by monitoring the peak area at different time intervals. \% RSD of the peak area was monitored from its initial level to $48 \mathrm{~h}$ and found less than $5.0 \%$, indicating that the standard solution is stable for about 48hours at room temperature.

\section{Linearity and range}

The test solutions concentration for Carvedilol is $1.0 \mathrm{mg} \mathrm{ml}^{-1}$. Considering the impurities limit levels $0.2 \%$, response function (peak area) was determined by preparing standard solution of each component (Carvedilol, Carvedilol EP Impurity-A, Carvedilol EP Impurity-B, Carvedilol EP Impurity-C and Carvedilol EP Impurity-D) at different concentration level ranging from lower limit of quantification to $150 \%$ limit level.

The graph of the peak area of the analytes relative to their respective concentrations is plotted and a linear ship was observed and they fitted straight lines responding to equation. Y-intercept bias at 100 $\%$ linearity level found less than $5.0 \%$. The correlation cféfients

(r) found greater than 0.99 the acceptance threshold for the quantification of impurity content in bulk drug.

Method found Linear in the range from Limit of Quantification (LOQ) to $150 \%$ level, considering the specification level $0.2 \%$ w. r. $t$. sample concentration. The residuals plot follow the random patterns with the residuals passing the normal distribution test $(p<0.05)$, all of which proves that the method is linear in the tested range. The Regression statistics of Linearity experimental results are shown in table 3 .

Table 3: Regression statistics of linearity experimental results

\begin{tabular}{lllll}
\hline Compound & Concentration $\boldsymbol{\mu g ~ \mathbf { ~ m l } ^ { - \mathbf { 1 } }}$ & Multiple R & Regression equation & F \\
\hline Carvedilol & 0.04 to 3.00 & 0.9998 & $\mathrm{y}=139510.1 \mathrm{x}-60.0$ & 15.2 \\
EP Imp.-A & 0.04 to 3.11 & 0.9999 & $\mathrm{y}=67384.6 \mathrm{x}-156.8$ & 15.1 \\
EP Imp.-B & 0.04 to 3.06 & 0.9998 & $\mathrm{y}=156349.4 \mathrm{x}-455.1$ & 15.1 \\
EP Imp.-C & 0.04 to 3.14 & 0.9998 & $\mathrm{y}=100096.5 \mathrm{x}-161.1$ & 1 \\
EP Imp.-D & 0.04 to 2.93 & 0.9998 & $\mathrm{y}=48648.3 \mathrm{x}-195.9$ & 0.0009 \\
\hline
\end{tabular}

\section{Determination of limit of quantification and detection (LOQ and LOD)}

Calibration curve method (established from Linearity experiment) used for the determination of Limit of Qufarattion (LOQ) and Limit of Detection (LOD).

By applying Residual standard deviation $(\sigma)$ method LOQ and LOD values were predicted. For predicted levels precision and accuracy was established.

The visuals method also considered to assess the signal to noise ratio of analyte peak.

$$
\begin{aligned}
& L O Q=10 \sigma / s \\
& L O D=3.3 \sigma / s
\end{aligned}
$$

Where,

$\sigma=$ residual standard deviation of response

$\mathrm{s}=$ slope of the calibration curve

Predicted and precise Limit of Quantification (LOQ) and Limit of Detection (LOD) values are shown in table 4.

\begin{tabular}{|c|c|c|c|c|c|}
\hline \multirow[t]{2}{*}{ Compound } & \multicolumn{2}{|l|}{ LOQ } & \multicolumn{2}{|l|}{ LOD } & \multirow[t]{2}{*}{ RF } \\
\hline & $\mu \mathrm{g} \mathrm{ml}^{-1}$ & $\% \mathrm{w} / \mathrm{w}^{*}$ & $\mu \mathrm{g} \mathrm{ml}^{-1}$ & $\% \mathrm{w} / \mathrm{w}^{*}$ & \\
\hline EP Impurity-A & 0.04 & 0.004 & 0.013 & 0.001 & 2.07 \\
\hline EP Impurity-B & 0.04 & 0.004 & 0.013 & 0.001 & 0.89 \\
\hline EP Impurity-C & 0.04 & 0.004 & 0.013 & 0.001 & 1.39 \\
\hline EP Impurity-D & 0.04 & 0.004 & 0.013 & 0.001 & 2.87 \\
\hline Carvedilol & 0.04 & 0.004 & 0.013 & 0.001 & 1.00 \\
\hline
\end{tabular}

Table 4: Limit of quantification, detection, response factor (LOQ, LOD and RF)

Note: $* \%$ w/w calculated w. r. t. sample concentration $\left(1000 \mu \mathrm{g} \mathrm{ml}^{-1}\right)$

\section{Determination of Response Factor (RF)}

The Linear calibration curves for all impurities and main drug (Carvedilol) were derived using the peak areas against their concentrations. The linear regression equation containing slope for all impurities and main drug and their concentration range were summarized in table 3.

The Response Factor (RF) was determined as the ratio of slope of the regression line of main drug component (Carvedilol) to that for each impurity and is listed in table 4 .

\section{Accuracy}

Accuracy was evaluated by the simultaneous quantification of analytes (impurities) in sample solutions prepared by adding the known amount of impurities to test sample.
The experiment was performed corresponding to four concentration levels at LOQ, $50 \%, 100 \%$ and $150 \%$ by considering the impurities specification level i.e. $0.2 \% \mathrm{w} / \mathrm{w}$ with respect to sample solution concentration.

The samples were prepared in triplicate at each level. The quantification of added impurities was calculated as per methodology by applying RF (response factor) of respective impurity.

The accuracy experimental results shows that approximately $80 \%$ to $120 \%$ recoveries were obtained for all known impurities and \% RSD for triplicate test sample preparation of recovery results found less than $10 \%$. Therefore, based on the recovery data (table 5 to table 9) the quantification of impurities that are mentioned in this report has been demonstrated to be accurate, precise for intended purpose and is adequate for routine analysis. 
Table 5: Recovery for carvedilol

\begin{tabular}{|c|c|c|c|c|}
\hline Carvedilol & Preparation & \% Recovery & Mean & \%RSD \\
\hline \multirow[t]{3}{*}{ LOQ } & 1 & 110.0 & 104.2 & 5.0 \\
\hline & 2 & 102.5 & & \\
\hline & 3 & 100.0 & & \\
\hline \multirow[t]{3}{*}{$50 \%$} & 1 & 94.0 & 93.9 & 0.2 \\
\hline & 2 & 93.7 & & \\
\hline & 3 & 93.9 & & \\
\hline \multirow[t]{3}{*}{$100 \%$} & 1 & 96.5 & 96.6 & 0.1 \\
\hline & 2 & 96.6 & & \\
\hline & 3 & 96.6 & & \\
\hline \multirow[t]{3}{*}{$150 \%$} & 1 & 98.1 & 98.0 & 0.1 \\
\hline & 2 & 98.0 & & \\
\hline & 3 & 98.0 & & \\
\hline
\end{tabular}

Table 6: Recovery for carvedilol EP impurity-A

\begin{tabular}{llll}
\hline Impurity-A & Preparation & \% Recovery & Mean \\
\hline LOQ & 1 & 97.5 & 93.3 \\
& 2 & 90.0 & 4.1 \\
$50 \%$ & 3 & 92.5 & 107.0 \\
& 1 & 106.7 & 0.5 \\
$100 \%$ & 2 & 107.7 & 107.9 \\
& 3 & 106.7 & 110.8 \\
$150 \%$ & 1 & 108.2 & 0.3 \\
& 2 & 107.7 & 0.7 \\
\end{tabular}

Table 7: Recovery for carvedilol EP impurity-B

\begin{tabular}{llll}
\hline Impurity-B & Preparation & \% Recovery & Mean \\
\hline LOQ & 1 & 97.6 & 97.6 \\
& 2 & 102.4 & 4.9 \\
$50 \%$ & 3 & 92.9 & 108.3 \\
& 1 & 109.5 & 1.3 \\
$100 \%$ & 2 & 108.6 & 107.3 \\
& 3 & 106.7 & 107.6 \\
$150 \%$ & 1 & 107.1 & 0.3 \\
& 2 & 107.1 & 110.4 \\
\end{tabular}

Table 8: Recovery for carvedilol EP impurity-C

\begin{tabular}{|c|c|c|c|c|}
\hline Impurity-C & Preparation & \% Recovery & Mean & \%RSD \\
\hline \multirow[t]{3}{*}{ LOQ } & 1 & 92.9 & 93.7 & 3.9 \\
\hline & 2 & 97.6 & & \\
\hline & 3 & 90.5 & & \\
\hline \multirow[t]{3}{*}{$50 \%$} & 1 & 104.8 & 103.8 & 0.9 \\
\hline & 2 & 103.8 & & \\
\hline & 3 & 102.9 & & \\
\hline \multirow[t]{3}{*}{$100 \%$} & 1 & 107.1 & 106.8 & 0.2 \\
\hline & 2 & 106.7 & & \\
\hline & 3 & 106.7 & & \\
\hline \multirow[t]{3}{*}{$150 \%$} & 1 & 109.8 & 110.4 & 0.5 \\
\hline & 2 & 110.5 & & \\
\hline & 3 & 110.8 & & \\
\hline
\end{tabular}

\section{Method precision and Intermediate precision}

Method precision experiment was evaluated by preparing six spike samples preparation by spiking the known impurities (EP ImpurityA, EP Impurity-B, EP Impurity-C and EP Impurity-D) at $0.2 \% \mathrm{w} / \mathrm{w}$ level with respective of test concentration $\left(1000 \mu \mathrm{g} \mathrm{ml}^{-1}\right)$.
Intermediate precision has been assessed by different analysts on different HPLC systems, on different columns on different days. The experiment was conducted same as method precision experiment by spiking the known impurities (EP Impurity-A, EP Impurity-B, EP Impurity-C and EP Impurity-D) at $0.2 \% \mathrm{w} / \mathrm{w}$ level with respective of test concentration. 
From the Method precision and Intermediate precision experiment results the method was found precise. Results $(\% \mathrm{w} / \mathrm{w})$ were calculated for known, unknown and total impurities for method precision and intermediate precision experiment. \%RSD was calculated for $(\% \mathrm{w} / \mathrm{w})$ known, unknown and total impurities and found less than 10\%. Overall \%RSD for (\%w/w) known, unknown and total impurities was calculated for method precision and intermediate precision experiment results $(n=12$ results, six from method precision and six from intermediate precision) and found less than $10.0 \%$

The results for method precisions and intermediate precision were listed in table 10 to table 12 reveal that the method has good reproducibility with acceptable precision.

Table 9: Recovery for carvedilol EP impurity-D

\begin{tabular}{llll}
\hline Impurity-D & Preparation & \% Recovery & Mean \\
\hline LOQ & 1 & 92.1 & 96.5 \\
& 2 & 92.1 & 7.9 \\
$50 \%$ & 3 & 105.3 & 100.3 \\
& 1 & 102.0 & 1.5 \\
$100 \%$ & 2 & 100.0 & 102.0 \\
& 3 & 99.0 & 0.0 \\
$150 \%$ & 1 & 102.0 & 104.7 \\
& 2 & 102.0 & 0.3 \\
\end{tabular}

Table 10: Comparison of method precisions and Intermediate precision results

\begin{tabular}{lllll}
\hline Name & MP* & IP* & MP* & IP* \\
\cline { 2 - 5 } & Imp-A & Imp-A & Imp-B \\
\hline Spike sample-1 & 0.20 & 0.20 & 0.20 & 0.20 \\
Spike sample-2 & 0.20 & 0.20 & 0.20 & 0.21 \\
Spike sample-3 & 0.20 & 0.20 & 0.20 & 0.21 \\
Spike sampel-4 & 0.20 & 0.20 & 0.20 & 0.21 \\
Spike sample-5 & 0.20 & 0.20 & 0.20 & 0.21 \\
Spike sample-6 & 0.20 & 0.20 & 0.20 & 0.21 \\
Mean & 0.20 & 0.20 & 0.0 & 0.21 \\
\%RSD & 0.0 & 0.0 & 0.21 \\
Overall Mean & 0.20 & & 2.5 \\
Overall \%RSD & 0.0 & & 0.0 \\
\hline
\end{tabular}

MP*: Method precision IP*: Intermediate precision.

Table 11: Comparison of method precisions and intermediate precision results

\begin{tabular}{lllll}
\hline Name & MP* & IP* & MP* & IP* \\
\cline { 2 - 5 } & Imp-C & Imp-C & Imp-D & 0.19 \\
\hline Spike sample-1 & 0.21 & 0.21 & 0.19 & 0.21 \\
Spike sample-2 & 0.21 & 0.21 & 0.18 & 0.21 \\
Spike sample-3 & 0.21 & 0.21 & 0.19 & 0.21 \\
Spike sampel-4 & 0.21 & 0.22 & 0.19 & 0.21 \\
Spike sample-5 & 0.21 & 0.22 & 0.19 & 0.19 \\
Spike sample-6 & 0.21 & 0.21 & 0.21 \\
Mean & 0.21 & 0.21 & 2.2 & 0.21 \\
\%RSD & 0.0 & 2.4 & 0.20 & 0.0 \\
Overall Mean & 0.21 & & 5.8 \\
\hline
\end{tabular}

MP*: Method precision IP*: Intermediate precision.

Table 12: Comparison of method precisions and intermediate precision results

\begin{tabular}{|c|c|c|c|c|}
\hline \multirow[t]{2}{*}{ Name } & MP* & IP* & MP* & IP* \\
\hline & Unknown imp.(SM*) & Unknown imp.(SM*) & Total impurities & Total impurities \\
\hline Spike sample-1 & 0.12 & 0.12 & 0.92 & 0.95 \\
\hline Spike sample-2 & 0.11 & 0.12 & 0.91 & 0.95 \\
\hline Spike sample-3 & 0.12 & 0.12 & 0.91 & 0.95 \\
\hline Spike sampel-4 & 0.12 & 0.12 & 0.92 & 0.96 \\
\hline Spike sample-5 & 0.11 & 0.12 & 0.91 & 0.96 \\
\hline Spike sample-6 & 0.11 & 0.12 & 0.91 & 0.95 \\
\hline Mean & 0.12 & 0.12 & 0.91 & 0.95 \\
\hline$\% \mathrm{RSD}$ & 4.8 & 0.0 & 0.6 & 0.5 \\
\hline Overall Mean & 0.12 & & 0.93 & \\
\hline Overall \%RSD & 3.8 & & 2.3 & \\
\hline
\end{tabular}

MP*: Method precision IP*: Intermediate precision. SM*: Single max 


\section{Robustness}

The robustness of the method has been demonstrated by verifying the system suitability parameters which meet the predefine acceptance criteria.

By making deliberate change in chromatographic conditions, i.e. change inflow rate by $\pm 0.1 \mathrm{ml} \mathrm{min}^{-1}$, change in column oven temperature by $+5{ }^{\circ} \mathrm{C}$, change in organic composition of mobile phase-A and mobile phase-B by+2\% absolute and change in wavelength by $5 \mathrm{~nm}$, system suitability parameters were verified for each above mentioned conditions.

System suitability criteria of method was meet at different robustness condition, Hence the method is robust over an acceptable working range of its HPLC operational conditions.

\section{CONCLUSION}

Analytical Method validation experimental results found within predefine acceptance criteria which prove that the method is linear in proposed working range, accurate and precise. There is no interference observed from blank, excipient for known and unknown impurities which prove that the method is specific and stability indicating in nature. The method is found robust for change in flow rate, change in column oven temperature, change in organic composition of mobile phase-A and mobile phase-B and change in wavelength.

Hence the proposed reverse phase HPLC analytical method can be used for impurity profiling of known, unknown impurities and degradent (which is formed during stability) analysis as well as routine analysis for Carvedilol tablets.

\section{ACKNOWLEDGMENT}

The author wish thanks to management of Maulana Azad College of Arts, Science and Commerce for providing excellent research facilities.

\section{FUNDING}

Nil

\section{AUTHORS CONTRIBUTIONS}

All the authors have contributed equally.

\section{CONFLICT OF INTERESTS}

Declare none

\section{REFERENCES}

1. FDA Approved Drug Products: Carvedilol Oral Tablets. Available from: https://www.accessdata.fda.gov/ drugsatfda_docs/label/2017/020297s038lbl.pdf. [Last accessed on 02 Jul 2021]

2. FDA Approved Drug Products: Carvedilol Oral Extended Release Capsules. Available from: https://www.accessdata.fda.gov/drugsatfda_docs/label/2017/ 022012s022lbl.pdf. [Last accessed on 02 Jul 2021]

3. Nakamura K, Kusano K, Nakamura Y, Kakishita M, Ohta K, Nagase S, Yamamoto M, Miyaji K, Saito H, Morita H, Emori T, Matsubara H, Toyokuni S, Ohe T. Carvedilol decreases elevated oxidative stress in human failing myocardium. Circulation. 2002 June 18;105(24):2867-71. doi: 10.1161/ 01.cir.0000018605.14470.dd, PMID 12070115.

4. Kukin ML, Kalman J, Charney RH, Levy DK, Buchholz Varley C, Ocampo ON, Eng C. Prospective, randomized comparison of effect of long-term treatment with metoprolol or carvedilol on symptoms, exercise, ejection fraction, and oxidative stress in heart failure. Circulation. 1999;99(20):2645-51. doi: 10.1161/01.cir.99.20.2645, PMID 10338457.

5. Varin F, Cubeddu LX, Powell JR. Liquid chromatographic assay and disposition of carvedilol in healthy volunteers. J Pharm Sci. 1986;75(12):1195-7. doi: 10.1002/jps.2600751218, PMID 3559930 .

6. Vander off BT, Ruppel HM, Amsterdam PB. Carvedilol: the new role of beta blockers in congestive heart failure. Am Fam Phys. 1998;58:1627-34
7. Nichols AJ, Gellai M, Ruffolo RR. Studies on the mechanism of arterial vasodilation produced by the novel antihypertensive agent, carvedilol. Fundam Clin Pharmacol. 1991;5(1):25-38. doi: 10.1111/j.1472-8206.1991.tb00698.x, PMID 1712335.

8. Ruffolo RR, Gellai M, Hieble JP, Willette RN, Nichols AJ. The pharmacology of carvedilol. Eur J Clin Pharmacol. 1990;38;Suppl 2:S82-8. doi: 10.1007/BF01409471, PMID 1974511.

9. Morgan T. Clinical pharmacokinetics and pharmacodynamics of carvedilol. Clin Pharmacokinet. 1994 May;26(5):335-46. doi: 10.2165/00003088-199426050-00002, PMID 7914479.

10. Gorog S, Babjak M, Balogh G, Brlik J, Csehi A, Dravecz F, Gasdag M, Horvath P, Lauko A, Varga K. Drug impurity profiling strategies. Talanta. 1997;44(9):1517-26. doi: 10.1016/S00399140(96)02179-0, PMID 18966892.

11. International Conference on Harmonization (ICH) Q3A (R2): Impurities in New Drug substance; 2006.

12. International Conference on Harmonization (ICH) Q3B (R2): Impurities in New Drug Products; June 2006.

13. FDA. Guidance for industry, analytical procedures and method validation for drug and biologics. United States Department of Health and Human Services Food and Drug Administration, Center for Drug Evaluation and Research (CDER), Center for Biologics Evaluation and Research (CBER); July 2015.

14. Bakshi M, Singh S. Development of validated stability-indicating assay methods-critical review. J Pharm Biomed Anal. 2002;28(6):1011-40. doi: 10.1016/s0731-7085(02)00047-x, PMID 12049968.

15. Swartz M, Krull I. Analytical method validation for biotechnology proteins, peptides and antibodies. LC GC North Am. 2009;27(7):550-75.

16. International Conference on Harmonization (ICH) Q2 (R1): Validation of Analytical Procedures Test and Methodology; November 2005.

17. Epshtein NA. Validation of HPLC techniques for pharmaceutical analysis. Pharm Chem J. 2004;38(4):212-28. doi: 10.1023/B:PHAC.0000038422.27193.6c.

18. Abdullah JW, Shariq H, Siddiqui JA. Method development and analytical method validation of carvedilol by high-performance liquid chromatography. J Pharm Biol Sci. 2016;11(6):93-7.

19. Ciobanu AM, Pop A, Crisan S, Pali M, Burcea-Drag G, Popa D. HPLC studies for assessing the stability of carvedilol tablets. Farmacia. 2017;65(4):523.

20. Savic I, Marinkovc V, Savic I, Sibinovic P, Cekic N. Application of the experimental design method to photostability studies of Karvileks tablet. Indian J Pharm Educ Res. 2012;43(3):275-82.

21. Sripalakit P, Kaewnok S, Tubtonglang S. Development of carvedilol assay in tablet dosage form using HPLC with fluorescence detection. Maejo Int J Sci Technol. 2010;4(01):8-19.

22. Mahaveer S, Kashkhedikar SG, Love S, Garg A, Tripti G, Patel A. Development of RP-HPLC method for estimation of carvedilol in tablet formulations. Res J Pharm Technol. 2008;1:1.

23. Uma V, Rao M, Haritha G, Krishnaiah T, Gouri T, Saikiran. Method development and forced degradation studies of carvedilol by RP-HPLC. Int J Pharm Anal Res. 2017;6(3):457-68.

24. Desai DC, Karkhanis VV. Simple spectrometric estimation of carvedilol phosphate in bulk and tablet dosage form. Int Res J Pharm. 2012;3(2).

25. Dey S, Kumar D, Sreenivas SA, Sandeep D. Analytical method development and validation of carvedilol by HPLC in bulk and dosage form. J Pharm Res. 2010;3(12):3075.

26. Patel LJ, Suhagia BN, Shah PB, Shah RR. RP-HPLC and HPTLC methods for the estimation of carvedilol in bulk drug and pharmaceutical formulations. Indian J Pharm Sci. 2006;68(6):790. doi: 10.4103/0250-474X.31017.

27. Myung SW, Jo CH. Gas chromatograph-mass spectrometric method for the determination of carvedilol and its metabolites in human urine. J Chromatogr B Analyt Technol Biomed Life Sci. 2005;822(1-2):70-7. doi: 10.1016/j.jchromb.2005.05.023, PMID 15996536.

28. Hossain MD, Kundu DR, Sharmin T, Maleque M, Chowdhury SR. A simple reversed phase high-performance liquid chromatography method development and validation for determination of carvedilol in pharmaceutical dosage forms. Int J Adv Pharm Anal. 2013;3:68-71. 
29. Nadella NP, Ratnakaram VN, Srinivasu N. Development and validation of UPLC method for simultaneous quantification of carvedilol and ivabradine in the presence of degradation products using DoE concept. J Liq Chromatogr Relat Technol. 2018;41(3):143-53.

doi: $10.1080 / 10826076.2018 .1427595$

30. Mali AD. Simultaneous determination of carvedilol and hydrochlothiazide in pharmaceutical dosage form by first order derivative UV spectrophotometry. Int J Pharm Sci. 2015;7(9):371-4.

31. Sajan PG, Rohith T, Patil P, Mantelingu K, Rangappa KS, Kumar MN. Rapid highly efficient and stability indicating RP-HPLC method for the quantitative determination of potential impurities of carvedilol active pharmaceutical ingredient. Int J Pharm Pharm Sci. 2014;6(10):214-20.
32. Stojanovic J, Marinkovic V, Vladimirov S, Velickovic D, Sibinovic $P$. Determination of carvedilol and its impurities in pharmaceuticals. Chromatographia. 2005;62(9-10):539-42. doi: 10.1365/s10337-005-0656-y.

33. Kang TC, GU, Xiao HE, Jia-jia. Determination of impurities D and E of carvedilol tablets by RP-HPLC. Chin J Pharm Anal. 2015;35(10):1838-42.

34. Raju TVR. Development and validation of stability-indicating impurity profiling method for the carvedilol in API and pharmaceutical formulation. Int J Pharmacol Pharm Sci. 2015;2(6):22-31.

35. Eisenberg EJ, Patterson WR, Kahn GC. High-performance liquid chromatographic method for the simultaneous determination of the enantiomers of carvedilol and its 0-desmethyl metabolite in human plasma after chiral derivatization. J Chromatogr B. 1989;493:105-15. doi: 10.1016/S0378-4347(00)82713-9. 